\title{
The appropriateness of treating psychopathic disorders
}

\author{
Alan R. Felthous*
}

Division of Forensic Psychiatry, Department of Neurology \& Psychiatry, Saint Louis University School of Medicine, Saint Louis, Missouri, USA

The received wisdom is that there is no known effective treatment for psychopathic disorders. Although outcome studies have not identified an effective programmatic treatment for psychopathic disorders, such studies tend to leave the question open. If behavioral science has not established that psychopathic disorders respond to a particular programmatic approach, neither are psychopathic disorders convincingly proven to be absolutely resistant to treatment. If no treatment is known to be effective in psychopathic disorders, then any treatment seems to squander resources. What is often missing from the discussion is effective therapeutic measures to treat other behaviors that often co-occur, if they do not represent a domain of pathology of psychopathic disorders, such as impulsive aggression. After a brief summary of results of programmatic treatment of psychopathic offenders, this review focuses on the pharmacotherapy of impulsive aggression in psychopathic disorders. If the impulsive aggression that occurs with psychopathic disorders can be better controlled, treatment can have substantial benefits and would be most appropriate.

Received 21 January 2015; Accepted 9 March 2015; First published online 24 April 2015

Key words: Antisocial personality disorder, impulsive aggression, pharmacotherapy, psychopathic disorders, treatment.

\section{Introduction}

Due to their assaultive, destructive, and other antisocial acts, individuals with psychopathic disorders inflict untold harm on themselves, acquaintances, and strangers. The damage they inflict and the attempts at safe management by the criminal justice system amount to considerable economic cost to society. Yet the fatalistic conventional wisdom is that no treatment is effective for psychopathic disorders. From this perspective, efforts at treatment are counterproductive and a misuse of limited resources. Attempts to treat and cure the core defect of psychopathy may be futile in light of current medical and behavioral science.

Here the term "psychopathic disorders" is used with the same meaning as that in the comprehensive handbook on the topic. ${ }^{1,2}$ The term follows "both taxonomical and dimensional approaches" and includes "diagnostic conditions characterized by antisocial behaviors," but not "all antisocial or criminal behaviors regardless whether a disorder exists." More specifically, psychopathic disorders include the Hare psychopathy concept and antisocial

* Address for correspondence: Alan R. Felthous, MD, Division of Forensic Psychiatry, Department of Neurology \& Psychiatry, Saint Louis University School of Medicine, 1438 South Grand Boulevard, Saint Louis, MO 63104, USA.

(Email: felthous@slu.edu) personality disorder (APD), as defined in the Diagnostic and Statistical Manual of Mental Disorders (DSM), now in the fifth edition (DSM-5). ${ }^{3}$ In identifying psychopathic disorders, most of the studies cited in this review relied on either a version of the Psychopathy Checklist or an edition of the DSM diagnostic manual.

The treatment of psychopathic disorders is not so much different from other chronic mental disorders, such as schizophrenia for example. The pathogenesis of the "core defect," if there is a single underlying defect, is neither fully understood nor curable by current therapeutic modalities. Yet with remarkable success, the more salient and disturbing symptoms of schizophrenia are treated, often with substantial improvement in overall functioning. If, instead of seeking to eliminate or overcome the "core defect" of psychopathy, treatment were to target specific troublesome cognitive, emotional, or behavioral symptoms, enough improvement might be attained to make treatment appropriate and worth the effort.

Reviewers who address the effectiveness of treating psychopathic disorders typically compare outcomes to programmatic approaches. Programs are different, psychopathic disorders vary in characteristics and severity, and follow-up treatment upon completing a given program is often lacking. Unsurprising then, studies produce apparently contradictory results, and reviews result in uncertain conclusions. After a brief summary of 
reviews of treatment programs, this article's main focus is on evidence-based pharmacotherapy of the impulsive aggression of psychopathic disorders. To be noted is that outcome studies of treatment programs do not include pharmacotherapy of specific domains of psychopathy as part of the treatment and analysis of effectiveness.

The main focus here will then be on the pharmacotherapy of impulsive aggression, for which evidencebased effectiveness has been demonstrated even within the pathological context of a personality or psychopathic disorder. Whether impulsive aggression is a co-occurring condition (i.e., intermittent explosive disorder), a direct manifestation of the psychopathic disorder for which it is a diagnostic criterion, or a "domain" of the disorder may be more of a semantic or conceptual than a therapeutically practical distinction. At any rate, effective treatment ought not to be withheld because the patient also meets criteria for a psychopathic disorder, such as APD as delineated in (DSM-5). ${ }^{3}$

\section{Programmatic Treatment for Psychopathic Offenders}

Whether a criminal offender's psychopathy is improved, worsened, or not affected by programmatic treatment remains unsettled. An attempt to categorize the nonpharmacotherapeutic approaches to treatment of personality and behaviorally disturbed criminal offenders in Canada and the United States showed the following approaches in use: the therapeutic community based on social learning, the token economy based on cognitive and/or behavioral therapy, and dialectic behavioral therapy. ${ }^{4}$ Psychosocial rehabilitation programs reduce untoward behaviors while offenders remain in such intramural programs, i.e., while they are still incarcerated. Where psychosocial therapeutic services are continued after release from prison, limited evidence suggests diminished recidivism. Those with severe psychopathy, however, do not consistently show this benefit after release. ${ }^{4}$ Conclusions from reviews that describe the nature of psychosocial rehabilitation programs must be tempered because reports of the methods and outcomes do not consistently describe the character pathology or measure the degree of psychopathy of the treated offenders. Moreover, descriptive reports of individual intramural psychosocial rehabilitation programs do not typically report continuing psychosocial programmatic or psychotherapeutic efforts in the community after offenders are released from prison. ${ }^{4}$

Apart from the literature that describes psychosocial rehabilitation programs for criminal offenders, a few reviews include only studies that consistently measure the degree of psychopathy. From these reviews and individual studies themselves, the nature of the treatment is not consistently and adequately described, and follow-up treatment after release from the intramural program is neglected. Where the programs are described, they are so fundamentally different that any comparison is like that of the proverbial apples and oranges.

Two examples of frequently cited, but with substantially different treatments for psychopathic disorders, are the reports by Rice et al. ${ }^{5}$ and by Skeem et al., respectively. The study by Rice et al. suggested that psychopathy could be made worse by treatment. Theirs was a highly atypical therapeutic community program at the Social Therapy Unit in Pentaguishene, Canada. Recidivism was lower for nonpsychopathic subjects with Psychopathy Checklist-Revised (PCL-R) scores less than 25, in comparison with nontreated subjects. Psychopathic subjects, however, recidivated regardless whether or not they received treatment, and the rate of violent recidivism was higher for treated psychopathy but lower for nontreated psychopaths. This study would favor treatment in this therapeutic community program for nonpsychopathic offenders, but not psychopathic offenders.

In contrast, the study by Skeem et al. examined the effects of treatment, not in a corrections-based intramural therapeutic community program, but in a civil setting wherein subjects were provided standard psychiatric treatment as outpatients. Pharmacotherapy, presumably tailored for individualized treatment plans, was used but not described in this report. Results of this study, using different Psychopathy Checklist-Revised, Screening Version (PCL-SV) cutoff scores than the study by Rice et al., indicated that subjects with "potentially psychopathic" personality disorders benefitted from ordinary follow-up treatment in the community if such treatment consisted of a sufficient number of sessions. This study by itself does not contradict the assumption that severe psychopathy does not show improvement following treatment, ${ }^{7}$ but the effect of adequate follow-up treatment for severe psychopathy is not clarified by either of these 2 studies. Importantly, the 2 studies illustrate how different "treatment" is between studies that are compared to assess the amenability of psychopathic disorders to programmatic treatment.

Seto and Barbaree's ${ }^{8}$ follow-up study of 224 sex offenders suggested that those who showed "good treatment behavior" while in the prison-based treatment program did not show diminished recidivism following release. Moreover, offenders who scored 15 or higher on the PLC-R and who demonstrated improved behavior during treatment were more likely to commit a serious offense. Together with the results by Rice et al., ${ }^{5}$ their study suggests that the risk of recidivism can be increased as a result of treatment.

Two hypotheses are proffered to explain how treatment could worsen the psychopathic criminal behavior. The first is because psychopaths are prone to manipulate, they are able to appear improved during treatment without actually benefitting from treatment. ${ }^{9}$ 
The "treatment-causes-harm" hypothesis suggests that psychopaths are only better armed to carry out their antisocial behavior as a result of treatment. ${ }^{10}$ Citing programs that were associated with increased postrelease criminal behavior, Hare ${ }^{10}$ concluded that it was the insight orientation approach of these particular programs that contributed to the worsened outcome of those with elevated psychopathy. He did not conclude from this disappointing finding that psychopathy is immutable to any treatment.

When Looman et al. ${ }^{11}$ attempted to replicate the study by Seto and Barbee, ${ }^{8}$ identifying psychopathy with a PCL-R cutoff of 25, they found that serious recidivism was related to psychopathy, but how well the subjects did during treatment did not affect their rates of serious recidivism. Similarly when Barbee ${ }^{9}$ examined the sample of offenders from the Seto and Barbee study over a longer period of follow up, he found that psychopathy remained a significant predictor of general and serious recidivism, but treatment behavior did not affect the rates of recidivism among psychopathic individuals, with 30 as the PCL-R cutoff.

In contrast, the review by Salekin et al. ${ }^{12}$ found that 3 out of 8 studies of adult subjects diagnosed with psychopathy showed treatment gains. Using a different method, D'Silva et al. ${ }^{13}$ reviewed studies on the effectiveness of treatment programs in the treatment of psychopathy. They first attempted to identify all published and unpublished studies of treatment programs that diagnosed psychopathy by a high score on the PCL-R or a derivative measure. Four questions were used to evaluate the quality of each study: (1) Was an adequate control group included? (2) Did the treatment focus on "Hare psychopathy"? (3) Were the outcome variables adequate? and (4) was the follow-up study of adequate length? The authors concluded that none of these studies was acceptable, and that a negative relationship between treatment response and elevated PCL scores has not been demonstrated. $^{13}$

Reviews and individual studies taken together neither establish effective treatment for psychopathic disorders nor justify the conclusion that such disorders are untreatable. From reviews of outcome studies of treatment programs for psychopathic individuals, conclusions about what is and what is not effective treatment cannot be made. The treatment itself is not well described in the reviews or sometimes in the studies themselves. ${ }^{7}$ If treatment is aimed at controlling and preventing offending behaviors, assessment and treatment of such behaviors by evidence-based treatment such as pharmacotherapy is not described; neither are measures of outpatient treatment or general relapse prevention following release from prison and from the in-service treatment program described, if such measures were attempted.

\section{Impulsive Aggression in Psychopathic Disorders}

It may well be that the core defect in psychopathy, if there is a single causal defect such as deficient capacity for empathy, is immutable to any pharmaceutical agent. Yet behaviors that are symptomatic of or co-occurring with psychopathic disorders are amenable to pharmacotherapy, and no less so because the individual is a psychopath. In this review, I use the term psychopathic disorders to include both Hare psychopathy ${ }^{10,14,15}$ and also the APD of the DSM. ${ }^{3}$

Physical aggression is one of the most serious manifestations and consequences of psychopathic disorders. Premeditated-also termed proactive, instrumental, and predatory-aggression appears to be most closely associated with psychopathic disorders. ${ }^{16-18}$ A classification of aggression based on the degree of thought and emotion involved in each consists of 4 types: impulsive, spontaneous, compulsive, and premeditated. ${ }^{19}$ Whether all 4 types are more commonly represented in psychopathic disorders remains to be determined empirically. If the spectrum of psychopathic disorders is extended to include the variously termed successful, ${ }^{20}$ creative, industrial, ${ }^{21}$ or corporate, ${ }^{22,23}$ then physical aggression is not such a pronounced manifestation of this latter condition for which there is no known pharmacotherapy. Premeditated aggression, i.e., the type that is conceptually most closely associated with psychopathic disorders, is not known to respond favorably to pharmacotherapy. ${ }^{24,25}$ However, impulsive aggression, which also occurs with psychopathic disorders, is often controlled with evidence-based pharmacotherapy. ${ }^{26}$

Although not completely defined, impulsive aggression corresponds to the following diagnostic criteria for APD in the DSM-5: "3. Impulsivity or failure to plan ahead; 4 . Irritability and aggressiveness, as indicated by repeated physical fights or assaults" (p. 659). ${ }^{3}$ Likewise impulsive aggression corresponds to the following criteria for APD that are included in the "Alternative DSM-5 Model for Personality Disorders," which was added in the fifth edition: "4. Hostility (an aspect of Antagonism): Persistent or frequent angry feelings; anger or irritability in response to minor slights and insults, mean, nasty or revengeful behavior. 5. Impulsivity (an aspect of Disinhibition): Acting on the spur of the moment in response to immediate stimuli; acting on a momentary basis without a plan or consideration of outcomes; difficulty establishing or following plans" (p. 764). ${ }^{3}$

The psychological instruments for assessment of psychopathy developed by Hare ${ }^{10}$ follow a dimensional rather than a categorical approach. The PCL-R is organized into a 2-part Factor Structure; Factor 1 represents affective and interpersonal components, and Factor 2 represents the more externalizing, socially deviant lifestyle of psychopathy. Within a superordinate 
4-factor model-interpersonal, affective, lifestyle, and antisocial-impulsive aggression could support 2 factors in particular: "impulsive" under lifestyle and "poor behavioral controls" under antisocial. The PCL Youth Version (PCL-YV) uses the term "poor anger control" rather than "poor behavioral controls."10

Thus impulsive aggression supports criteria for APD under DSM-5, as well as factors of Hare psychopathy.

\section{Primary Impulsive Aggression}

Once impulsive aggression has been diagnosed, a determination must be made as to whether it is primary or secondary to another medical, neurological, or medical condition. If what is basically phenomenologically impulsive aggression is secondary to a mental disorder with known efficacious pharmacotherapy for the other mental disorder-schizophrenia, delusional disorder, bipolar disorder, or traumatic brain injury, for examplethe impulsive aggression may well come under control with appropriate treatment of the primary mental disorder, the treatment of which has been discussed in several reviews. ${ }^{26-30}$ Here we are interested in primary impulsive aggression, i.e., impulsive aggression that is not due to a mental disorder other than personality or psychopathic disorder.

Identification of primary impulsive aggression that co-occurs with a personality or psychopathic disorder begs the question as to whether the impulsive aggression is secondary to the character pathology. Impulsive aggression in particular may distinguish the unsuccessful from the successful psychopath ${ }^{21-23,31,32}$ and causes the unsuccessful psychopath to be preferentially subjected to arrest and incarceration. As shown above, aggressive behavior is a diagnostic criterion for APD and the conduct disorder in youth from which it evolves, as well as an element of the dimension of psychopathy described and measured by Hare. ${ }^{10,14,15}$

Borderline personality disorder (BPD) is another Cluster B personality disorder for which impulsive and aggressive behavior can be diagnostic criteria. ${ }^{3}$ Just as in APD or psychopathy, impulsive aggression can be a manifestation of BPD. However, the effect of divalproex in reducing impulsive aggression in $\mathrm{BPD}$, an effect independent of that on the emotional dysregulation of BPD, led Hollander and colleagues ${ }^{33-35}$ to conceptualize impulsive aggression as one of several "domains" of BPD.

A conceptualization of impulsive aggression as a domain of psychopathy may be equally justified and consistent with the dimensional approach in the second research criterion of APD. ${ }^{3}$ If a dimension or domain is part of the disorder, then the disorder itself, BPD or APD, is being treated pharmacotherapeutically and efficaciously, even if the medication does not affect all symptoms of the disorder. Nonetheless, the distinction of primary impulsive disorder is useful, even if it is a manifestation of character pathology from which it is thought to be secondary. At the same time, the domain approach and the possibility of differential pharmacotherapeutic effects on impulsive aggression raise the possibility of different types of "primary impulsive aggression."

\section{The Neurobiology of the Factor Domains of Psychopathy}

Although relevant, it would be beyond the scope of this review to provide an update on the considerable literature on the childhood development, psychosocial evolution, and neurobiology of psychopathic disorders. For a more complete discussion of these and other dimensions of the etiology and pathogenesis of psychopathic disorders, the reader is referred to The International Handbook of Psychopathic Disorders and the Law, Volume I: Diagnosis and Treatment. ${ }^{36}$ Some authors provide a translational approach to the theory and practice of the pharmacotherapy of aggressive behavior. ${ }^{37,38}$ The emphasis in this review is more on empirical evidence for treatment efficacy than therapeutic mechanisms. Nonetheless, the potential theoretical importance of the prefrontal cortex, the orbital frontal cortex in particular, and the temporal lobes, especially the amygdala, may be of particular relevance to both psychopathy $^{39}$ and impulsive aggression. In controlling impulsive aggression, fluoxetine is a selective serotonin reuptake inhibitor (SSRI) with demonstrable effect on the prefrontal cortex; whereas certain anticonvulsants, stabilize neurons of the amygdala in particular.

Two biological correlates of impulsive aggression are abnormally low amplitude of the P300 event-related potential and evidence of hyposerotonicity in the prefrontal cortex, both of which may pertain to the therapeutic effects of anti-impulsive aggressive agents (AIAAs). Phenytoin normalizes the low amplitude of P300 of impulsively aggressive subjects and reduces their aggression, but has no effect on the already normal amplitude of the P300 and premeditated aggressive episodes in subjects with antisocial personality disorder. $^{24,25}$ Evidence for hyposerotonicity in the prefrontal cortex, which has been shown to be associated with impulsive aggression, ${ }^{40}$ may be improved with SSRIs such as fluoxetine. Fluoxetine can reduce impulsive aggression, which in psychopathy corresponds to its impulsive-antisocial factor. ${ }^{41}$

Suggesting a pathophysiological distinction between impulsive aggression and callousness are the differential degrees of 5-HT transporter (5-HTT) binding at different locations in the brain. Van de Giessen et al. ${ }^{42}$ recently found a positive correlation between 5 -HTT availability in the pregenual anterior cingulated cortex (pgACC) and 
callousness, whereas subjects with intermittent explosive disorder (IED) showed no differences in 5-HTT binding in comparison with controls. Therefore, while impulsive aggression is associated with hyposerotonicity, especially in the frontal cortex, ${ }^{40}$ the callousness domain of psychopathic disorders may also be related to aberrant serotonin availability, even if increased and in a different part of the brain.

Speculative to be sure, but perhaps future research will further clarify this possibility of specific abnormal serotonicity with callousness, which suggests a pharmacotherapeutic intervention for callousness as a trait that enables premeditated aggression. For now, it is sufficient to recognize the amenability of impulsive aggression to pharmacotherapy, including the use of fluoxetine, an SSRI thought to ameliorate the hyposerotonicity of impulsive aggression.

Doland and Anderson ${ }^{43}$ suggested that the construct of psychopathy is sufficiently complex that further investigation ought to examine the neurobiological correlates of each factor-impulsive-antisocial, arrogant/deceitful, and callous/remorseless, respectivelyrather than the unified construct of the so-called prototypical psychopath. They anticipate, as does this author, that this more discerning approach will be more productive in studying the pharmacotherapy of psychopathic disorders. I maintain that the distinction between impulsive aggression, consistent with impulsiveantisocial conduct, and premeditated aggression, compatible with arrogant/deceitful and/or callous/remorseless trait factors, already informs the pharmacotherapy of psychopathic disorders, namely the pharmacotherapeutic target of impulsive but not premeditated aggression.

\section{Pharmacotherapy of Aggression in Psychopathic Disorders}

As in any patient, including patients with personality disorders and psychopathic disorders, pharmacotherapy should not be initiated until the nature of the aggression has been evaluated. ${ }^{26,44-46}$ Although those with psychopathic disorders can show various types of untoward aggression, and premeditated or proactive aggression is thought to be the most characteristic of psychopathy, impulsive aggression also commonly occurs with psychopathic disorders. It is the physical aggressiveness of some antisocial or psychopathic disordered individuals that makes their condition so problematic and dangerous to others. In the prison studies by Barratt et al., ${ }^{24,25}$ all aggressive subjects, both those with predominantly impulsive aggression and those with predominantly premeditated aggression, met the criteria for APD.

In general, those who meet the criteria for IED can be said to have impulsive aggression, but DSM-5 discourages the diagnosis and thereby the treatment of
IED in those with APD by its exclusionary criterion. If "recurrent aggressive outbursts are not better explained by ... e.g., antisocial personality disorder" (p. 466), ${ }^{3}$ then the diagnosis of IED is permissible. This exclusionary criterion would likely mislead many clinicians to avoid the diagnosis and treatment of IED in the context of an antisocial personality disorder. Yet the clinician, who is knowledgeable about the different types of aggression and their different amenabilities to pharmacotherapy, can provide effective pharmacotherapy for abnormal aggression that occurs with antisocial personality disorder without violating this exclusionary criterion.

We should note carefully the wording of this exclusion. It does not exclude the diagnosis of IED co-occurring with $\mathrm{APD}$, but recurrent aggressive behavior that is better explained by APD. To the extent that premeditated or proactive aggressive behavior is more typical of APD and psychopathic disorders, premeditated aggression should not be diagnosed as IED and neither does it fit the description. Impulsive aggression, although often co-occurring with APD, is not thought to be such a specific manifestation of the core defect. We will not here resolve the question as to what extent IED or impulsive aggression is symptomatic of APD and psychopathic disorders versus a frequent, co-occurring condition. Suffice it to say that the diagnosis of impulsive aggression ought not be withheld because the individual is diagnosed with APD or psychopathy. An analogy can be made with substance use disorder (SUD), which occurs with such frequency in psychopathic disorders that it is considered part of the symptomatic constellation. Yet the diagnosis of SUD is made separately, and treatment and rehabilitation are not categorically withheld because of the psychopathic disorder.

What is more meaningful than the exclusionary criterion of DSM-5 is the empirical data from research on aggressive subjects with personality disorders. Where impulsive aggression is diagnosed, it has been found to be amenable to pharmacotherapy regardless of whether it co-occurs with a personality or psychopathic disorder. Fluoxetine has been shown to be effective in the treatment of impulsive aggression in individuals with personality disorders such as $\mathrm{BPD},{ }^{47}$ and phenytoin has controlled impulsive aggression in prisoners with APD. ${ }^{24,25}$ Of decisive importance is the diagnosis of impulsive aggression and distinguishing impulsive from premeditated aggression. Premeditated aggression is singularly unresponsive to pharmacotherapy. ${ }^{24,25}$

Here the concept of impulsive aggression is favored over IED, because the former is better grounded in drug trial research, is not confounded by the earlier exclusion of IED that is associated with generalized impulsivity, and, unlike the DSM criteria for IED, does not mislead clinicians away from the diagnosis simply because the condition co-occurs with APD. ${ }^{45}$ Nonetheless, IED is impulsive aggression and should be treated accordingly. 
Once impulsive aggression has been diagnosed, psychotherapy and/or pharmacotherapy can be initiated. Here the discussion is limited to pharmacotherapy and the selection of the most promising anti-impulsive aggressive agent (AIAA). Guidelines for selecting an efficacious AIAA begin with an accurate diagnosis of impulsive aggression ${ }^{45}$-a step that is not uncommonly overlooked in AIAA drug trials and literature reviews, ${ }^{44}$ and presumably in clinical practice. Assessment of impulsive aggression has been discussed previously, ${ }^{45}$ and so is not iterated here.

\section{Selecting an AIAA}

For optimal efficacy and safety, 8 guidelines have been proffered by Felthous and Stanford ${ }^{46}$ for selecting an AIAA for control of a patient's impulsive aggression. Although some of these guidelines would be prudent for the prescription of any psychotropic medication, they are especially important in the selection of an AIAA, none of which has been approved by the FDA for this indication.

Steps to follow in selecting an AIAA are as follows:

1. Diagnose the condition as impulsive aggression.

2. Identify the agents with evidence of efficacy by drug trials of satisfactory quality.

3. Determine the risks of side effects for the individual patient.

4. Determine the severity of the outbursts.

5. Determine whether the patient has a co-occurring condition for which the AIAA is indicated.

6. Obtain the patient's pharmacotherapeutic history.

7. Determine if the AIAA is affordable and available to the patient.

8. Determine how urgently the aggressive behavior must be brought under control. ${ }^{46}$

Comment will be made on each of these factors, as the appropriateness of treating symptoms of psychopathic disorders depends on the logic of selecting the most appropriate AIAA.

The first 2 factors are of fundamental importance: identifying AIAAs that are efficacious and diagnosing impulsive aggression. In identifying efficacious AIAAs, 2 reports are especially useful. The meta-analysis by Jones et $a l .^{48}$ that examined the efficacy of mood stabilizers in reducing impulsive aggression also took into account measures for ensuring the quality of these studies. This meta-analysis supported the efficacy of carbamazepine/oxcarbazepine, phenytoin, and lithium, but not valproate or levetiracetam. ${ }^{48}$ In contrast to the negative finding concerning valproate, Hollander et al. ${ }^{34,35}$ provided evidence of the efficacy of divalproex in controlling impulsive aggression within the context of cluster B personality disorders and borderline personality disorder in particular. ${ }^{49}$
Felthous and Stanford ${ }^{46}$ reviewed 55 peer-reviewed studies on the pharmacotherapy of impulsive aggression. Of these, 23 satisfied inclusion criteria for quality placebo-controlled drug trials. Agents that were subjected to high quality drug trials included the anticonvulsants carbamazepine, divalproex/valproate, levetiracetam, oxcarbazepine, and phenytoin; the mood stabilizer lithium; the antipsychotic haloperidol; the antidepressant fluoxetine; and the amphetamines $\mathrm{d}$-amphetamine and pindolol. Only levetiracetam showed no efficacy. ${ }^{50}$ Those AIAAs that have been shown to be efficacious in more than one high-quality study and therefore constituting the most appropriate selections for AIAA are carbamazepine/oxcarbazepine, ${ }^{51-53}$ divalproate/valproate ${ }^{34,51,54}$ phenytoin, ${ }^{24,25}$ lithium, ${ }^{55-57}$ and fluoxetine. ${ }^{58,59}$

Importantly, these drug trials concern the pharmacotherapy of impulsive aggression, not undefined aggression or disruptive behavior. Some algorithms have been developed for the treatment of aggression due to various mental disorders, but not impulsive aggression in particular. $^{27-30}$ Impulsive aggression is the type of aggression that is most likely to be subject to improvement with an AIAA. Impulsive aggression should not be neglected just because it occurs together with a psychopathic disorder, any more than one would neglect treatment of a primary mental disorder such as major depressive disorder that co-occurs with a psychopathic disorder. Of critical importance is the careful diagnosis of impulsive aggression and distinguishing it from premeditated aggression, which is also common in psychopathic disorders but is not improved with an AIAA.

Consideration of risks and side effects for the individual patient is especially important, as none of these agents is FDA approved for the treatment of impulsive aggression or IED. Severity of the outbursts will help to identify the aggression as high-frequency/ low-intensity or low-frequency/high-intensity IED as detailed in DSM-5. ${ }^{3}$ Fluoxetine has been most studied with the former, and so would be a reasonable first choice in the treatment of less severe impulsive aggression. Fluoxetine is more conveniently administered, as serum levels are not needed, and its side effect profile is favorable compared with other AIAAs. The patient may have co-occurring disorders that favor one or more AIAA over the other, phenytoin for seizure disorder for example, whereas levetiracetam would not have such a " 2 for 1 " advantage. Naturally the pharmacotherapeutic history should not be overlooked. One of the AIAAs might have been prescribed for another purpose but with concomitant reduction in aggressive behavior. Affordability is critical for medication compliance, and insurance may not always cover the best selection of an AIAA for impulsive aggression. Finally if the need to bring impulsive aggression under control is 
urgent, there is evidence that phenytoin may begin to take effect quickly. ${ }^{26,60}$

Note that none of these considerations in selecting an AIAA pertains to whether or not the patient has a psychopathic disorder. The most important diagnostic question is whether the patient has impulsive aggression, which often but not always is found in psychopathic disorders.

\section{Conclusions}

Although the presence of a psychopathic disorder complicates and worsens the prognosis for successful treatment aimed at reducing general and violent recidivism, such a guarded outlook does not mean that treatment is necessarily inappropriate or without benefit. A potentially useful approach is to assess and treat particular domains of psychopathy for which treatment effectiveness has been demonstrated. The psychopathic individual's pattern of violent behavior, for example, can be evaluated. If his untoward aggression is predominantly impulsive, then a trial on an AIAA is indicated. Assessing the nature of an individual's aggression and considering an AIAA if he manifests predominantly impulsive aggression ought not to be neglected because he is diagnosed with a psychopathic disorder. This approach could inform programmatic treatment and outcome studies. Then outcome studies will advance our knowledge, not just about the appropriateness of treating psychopathic disorders, but about which treatments are effective for which domains of the disorder.

\section{Disclosure}

The author does not have anything to disclose.

\section{REFERENCES:}

1. $\mathrm{Sa} \mathrm{H}$, Felthous AR. Introduction to Volume 1. In: Felthous AR, $\mathrm{Sa} 3 \mathrm{H}$, eds. The International Handbook of Psychopathic Disorders and the Law, Volume I: Diagnosis and Treatment. Chichester, UK: John Wiley and Sons, Ltd.; 2007: 1-5.

2. $\mathrm{Sa} \beta \mathrm{H}$, Felthous AR. History and development of psychopathic disorders. In: Felthous AR, $\mathrm{Sa} \beta \mathrm{H}$, eds. The International Handbook of Psychopathic Disorders and the Law, Volume I: Diagnosis and Treatment. Chichester, UK: John Wiley and Sons, Ltd.; 2007: 9-30.

3. American Psychiatric Association. Diagnostic and Statistical Manual of Mental Disorders. 5th ed. Washington, DC: Arlington, VA; 2013.

4. Felthous AR, Sass H. Behandlungsprogramme für Straftäter in den Vereinigten Staaten und Kanada. In: Kröber HL, Dölling D, Leygraf N, Sass H, eds. Handbuch der Forensischen Psychiatrie, Band 3, Psychiatrische Kriminalprognose und Kriminaltherapie. Darmstadt, Germany: Steinkoff; 2006: 390-412.

5. Rice ME, Harris GT, Cormier C. Evaluation of a maximum security therapeutic community for psychopaths and other mentally disordered offenders. Law Hum Behavior. 1992; 16(4): 399-412.
6. Skeem JL, Monahan J, Mulvey EP. Psychopathy, treatment and involvement, and subsequent violence among civil psychiatric patients. Law Hum Behavior. 2002; 26(6): 577-603.

7. Felthous AR. The "untreatability" of psychopathy and hospital commitment in the USA. Int J Law Psychiatry. 2011; 34(6): 400-405

8. Seto MC, Barbaree HE. Psychopathy, treatment behavior and sex offender recidivism. J Interpers Violence. 1999; 14(12): 1235-1248.

9. Barbaree HE. Psychopathy, treatment behavior and recidivism: an extended follow-up of Seto and Barbaree. J Interpers Violence. 2005; 20(9): 1115-1131.

10. Hare RD. Psychological instruments in the assessment of psychopathy. In: Felthous AR, $\mathrm{Sa} \beta \mathrm{H}$, eds. The International Handbook of Psychopathic Disorders and the Law, Volume I: Diagnosis and Treatment. Chichester, UK: John Wiley and Sons, Ltd.; 2007: 41-67.

11. Looman J, Abracen J, Serin R, Marquis P. Psychopathy, treatment change and recidivism in high risk high need sexual offenders. J Interpers Violence. 2005; 20(5): 549-568.

12. Salekin RT, Worley C, Grimes RD. Treatment of psychopathy: a review and brief introduction to the mental model approach for psychotherapy. Behav Sci Law. 2010; 28(2): 235-266.

13. D'Silva K, Duggan D, McCarthy L. Does treatment really make psychopaths worse? A review of the evidence. J Personal Disord. 2004; 18(2): 163-177.

14. Hare RD. The Hare Psychopathy Checklist-Revised. Toronto, Canada: Multi-Health Systems; 1991.

15. Hare RD. Without Conscience: The Disturbing World of the Psychopaths Among Us. New York: Guilford Press; 1998.

16. Cornell D, Warren J, Hawk G, Stafford E, Oram G, Pine D. Psychopathy in instrumental and reactive offenders. J Consult Clin Psychol. 1996; 64(4): 783-790.

17. Patrick CJ. Emotional processes in psychopathy. In: Raine A, Sanmartin J, eds. Violence and Psychopathy. New York: Kluwer/ Plenum; 2001: 57-77.

18. Raine A, Yang Y. The neuroanatomical bases of psychopathy: a review of brain imaging findings. In: Patrick CJ, ed. Handbook of Psychopathy. New York: Guilford; 2006: 278-295.

19. Felthous AR. Schizophrenia and impulsive aggression: a heuristic inquiry with forensic and clinical implications. Behav Sci Law. 2008; 26(6): 735-758.

20. Babiak P, Hare RD. Snakes in Suits: When Psychopaths Go to Work. New York: Harper-Collins; 2006.

21. Babiak P. When psychopaths go to work: a case study of an industria psychopath. Applied Psychology. 1995; 44(2): 171-188.

22. Babiak P. Psychopathic manipulation at work. In: Gacono CB, ed. The Clinical and Forensic Assessment of Psychopathy: A Practitioner's Guide. Mahwah, NJ: Erlbaum; 2000: 287-311.

23. Babiak P, Neumann CS, Hare RD. Corporate psychopathy: talking the walk. Behav Sci Law. 2010; 28(2): 174-193.

24. Barratt ES, Standford MS, Felthous AR, Kent TA. The effects of phenytoin on impulsive and premeditated aggression: a controlled study. J Clin Psychopharmacol. 1997; 17(5): 341-349.

25. Barratt ES, Stanford MS, Kent TA, Felthous A. Neurological and cognitive psychophysiological substrates of impulsive aggression. Biol Psychiatry. 1997; 41(10): 1045-1061.

26. Felthous AR. The pharmacotherapy of impulsive aggression. In: Thienhaus OJ, Piaski M, eds. Correctional Psychiatry: Practice Guidelines and Strategies, Volume II. Kingston, NJ: Civil Research Institute; 2013: 4-1-4-34.

27. Glancy GD, Knott TF. Part I: The psychopharmacology of long-term aggression-toward and evidence-based algorithm. CPA Bulletin. 2002; 34(6): 13-18.

28. Glancy GD, Knott TF. Part II: The psychopharmacology of longterm aggression-toward an evidence-based algorithm. CPA Bulletin. $2002 ; 34(6)$ : $14-24$ 
29. Glancy GD, Knott TF. Part III: The psychopharmacology of longterm aggression-toward an evidence-based algorithm. CPA Bulletin 2003; 35(1): 18.

30. Moeller FG, Swann A. Pharmacotherapy of clinical aggression in individuals with psychopathic disorders. In: Felthous AR, $\mathrm{Sa} \beta \mathrm{H}$, eds. The International Handbook of Psychopathic Disorders and the Law, Volume I: Diagnosis and Treatment. Chichester, UK: John Wiley \& Sons, Ltd.; 2007: 397-416.

31. Babiak P. From darkness into the light: psychopathy in industrial and organizational psychology. In: Hervé $\mathrm{H}$, Yville $\mathrm{C}$, eds. The Psychopath: Theory, Research and Practice. Mahwah, NJ: Erlbaum; 2007: 411-428.

32. Gao Y, Raine A. Successful and unsuccessful psychopaths: a neurobiological model. Behav Sci Law. 2010; 28(2): 194-210.

33. Taylor BP, Weiss M, Ferretti CJ, et al. Disruptive, impulse-control, and conduct disorders. In: Hales RE, Yudofsky SC, Roberts LW, eds American Psychiatric Publishing Textbook of Psychiatry, 6th ed. Washington, DC: American Psychiatric Publishing; 2014: 703-734.

34. Hollander E, Tracy KA, Swann AC, et al. Divalproex in the treatment of impulsive aggression: efficacy in cluster B personality disorder. Neuropsychopharmacology. 2003; 28(6): 1186-1197.

35. Hollander E, Swann AC, Coccaro EF, Jiang P, Smith TB. Impact of trait impulsivity and state aggression in divalproex versus placebo response in borderline personality disorder. Am J Psychiatry. 2005; 162(3): 621-624.

36. Felthous $\mathrm{AR}, \mathrm{Sa} \beta \mathrm{H}$, eds. The International Handbook of Psychopathic Disorders and the Law, Volume I: Diagnosis and Treatment. Chichester, UK: John Wiley and Sons, Ltd.; 2007.

37. Comai S, Tau M, Gobbi G. The psychopharmacology of aggressive behavior: a translational approach. Part 1: Neurobiology. J Clin Psychopharmacol. 2012; 32(1): 83-94.

38. Comai S, Tau M, Pavlovic Z, Gobbi G. The psychopharmacology of aggressive behavior: a translational approach. Part 2: Clinical studies using atypical antipsychotics, anticonvulsants, and lithium. J Clin Psychopharmacol. 2012; 32(2): 237-260.

39. Blair JR. Neurobiological basis of psychopathy. Br J Psychiatry. $2003 ; \mathbf{1 8 2}(1): 5-7$.

40. Siever LJ, Buchsbaum MS, New AS, et al. D,l-fenfluramine response in impulsive personality disorder assessed with $\left[{ }^{18} \mathrm{~F}\right]$ fluorodeoxyglucose positron emission tomography. Neuropsychopharmacology. 1999; 20(5): 413-423.

41. Cooke DS, Mitchie C, Hart SD, Hare RD. Evaluating the Screening Version of the Hale Psychopathy Checklist-Revised (PCL-SV). Psychol Assess. 1999; 11(1): 3-13.

42. van de Giessen E, Rosell DR, Thompson JL, et al. Serotonin transporter availability in impulsive aggressive personality disordered patients: a PET study with $\left[{ }^{11} \mathrm{C}\right]$ DASB. J Psychiatr Res. 2014; 58: 147-154.

43. Dolan MC, Anderson IM. The relationship between serotonergic function and the Psychopathy Checklist: Screening Version. J Psychopharmacol. 2003; 17(2): 216-222.

44. Felthous AR, Lake SL, Rundle BK, Stanford MS. Pharmacotherapy of impulsive aggression: a quality comparison of controlled studies. J Int Law Psychiatry. 2013; 36(3-4): 258-263.
45. Felthous AR, Barratt ES. Impulsive aggression. In: Coccaro EF, ed. Aggression: Psychiatric Assessment and Treatment. New York: Marcel Dekker; 2003: 123-148.

46. Felthous AR, Stanford MS. A proposed algorithm for the pharmacotherapy of impulsive aggression. J Am Acad Psychiatry Law. 2015; 43(4).

47. Coccaro EF, Kavoussi RJ. Fluoxetine and impulsive aggressive behavior in personality disordered subjects. Arch Gen Psychiatry. 1997; 54(12): 1081-1088.

48. Jones RM, Arlidge J, Gilham S, Reagu S, van den Bree M, Taylor PJ. Efficacy of mood stabilizers in the treatment of impulsive or repetitive aggression: systematic review and meta-analysis. $\mathrm{Br} J$ Psychiatry. 2011; 198(2): 93-98.

49. Hollander E, Swann AC, Coccaro EF, Jiang P, Smith TB. Impact of trait impulsivity and state aggression on divalproex versus placebo response in borderline personality disorder. Am J Psychiatry. 2005; 162(3): 621-624.

50. Mattes JA. Levetiracetam in patients with impulsive aggression: a double-blind, placebo-controlled trial. J Clin Psychiatry. 2008; 69(2): 310-315.

51. Stanford MS, Helfritz LE, Conklin SM, et al. A comparison of anticonvulsants in the treatment of impulsive aggression. Exp Clin Psychopharmacol. 2005; 13(1): 72-77.

52. Cueva JE, Overall JE, Small AM, Armenteros JL, Perry R, Campbell M Carbamazepine in aggressive children with conduct disorder: a double-blind and placebo-controlled study. J Am Acad Child Adolesc Psychiatry. 1996; 35(4): 480-490.

53. Mattes JA. Oxcarbazepine in patients with impulsive aggression: a double-blind, placebo-controlled trial. J Clin Psychopharmacol. $2005 ; \mathbf{2 5}(6)$ : 575-579.

54. Donovan SJ, Stewart JW, Nunes EV, et al. Divalproex treatment for youth with explosive temper and mood lability: a double-blind, placebo-controlled crossover design. Am J Psychiatry. 2000; 157(5): 818-820.

55. Campbell M, Adams PB, Small AM, et al. Lithium in hospitalized aggressive children with conduct disorder: a double-blind, placebocontrolled study. J Am Acad Child Adolesc Psychiatry. 1995; 34(4): 445-453.

56. Campbell M, Small AM, Green WH, et al. Behavioral efficacy of haloperidol and lithium carbonate: a comparison in hospitalized aggressive children with conduct disorder. Arch Gen Psychiatry. 1984; 41(7): 650-656.

57. Sheard MH, Marini JL, Bridges CI, Wagner E. The effect of lithium on impulsive aggression behavior in man. Am J Psychiatry. 1976; 133(12): 1409-1413.

58. Coccaro EF, Lee RJ, Kavoussi RJ. A double-blind randomized, placebo-controlled trial of fluoxetine in patients with intermittent explosive disorder. J Clin Psychiatry. 2009; 70(5): 653-662.

59. Lee R, Kavoussi RJ, Coccaro EF. Placebo-controlled, randomized trial of fluoxetine in the treatment of aggression in male intimate partner abuse. Int Clin Psychopharm. 2008; 23(6): 337-341.

60. Pritchard WS, Barratt ES, Faulk DM, Brandt ME, Bryant SG. Effects of phenytoin on N100 augmenting/reducing and late positive complex of the event related potential: a topographical analysis. Neuropsychobiology. 1986; 15(3-4): 201-207. 